\title{
Seleção de uma abordagem de gestão de investimentos em Sistemas e Tecnologias da Informação
}

\author{
Jorge Gomes ${ }^{1}$, Mário Romão ${ }^{2}$ \\ jorgemvgomes@hotmail.com, mario.romao@iscte.pt \\ ${ }^{1}$ ISCTE, Instituto Universitário de Lisboa, Ava das Forças Armadas, 1649-026 Lisboa, Portugal \\ ${ }^{2}$ ISCTE, Instituto Universitário de Lisboa, Ava das Forças Armadas, 1649-026 Lisboa, Portugal
}

DOI: $10.4304 /$ risti.10.35-50

\begin{abstract}
Resumo: Vivemos um período de rápidas e desafiantes transformações tecnológicas. As organizações confrontam-se com oportunidades de implementação de novos Sistemas e Tecnologias de Informação (SI/TI) convictas de que os investimentos realizados lhes permitem aumentar a produtividade e a prosperidade do negócio. No entanto, vários estudos efectuados em organizações públicas e privadas comprovaram que os investimentos efectuados em SI/TI nem sempre trouxeram o benefício que deles se esperava. Um dos aspectos fundamentais que se coloca na gestão dos investimentos em SI/TI é a identificação dos benefícios potenciais e a garantia que estes, de facto, poderão ser realizados. Pela dificuldade sistemática na determinação dos benefícios, em especial dos benefícios intangíveis, a aplicação de métodos económico-financeiros não é evidente e portanto torna-se crucial, neste contexto, que as empresas introduzam abordagens de gestão que permitam identificar, monitorizar e alcançar os almejados benefícios. Neste artigo os autores seleccionam uma abordagem de gestão de investimentos em SI/TI, promovendo um processo comparativo que leva em conta a natureza dos investimentos e o ambiente organizacional onde se inserem.
\end{abstract}

Palavras-chave: Investimentos SI/TI; Benefícios do negócio SI/TI, Realização de Benefícios em Investimentos SI/TI; Gestão de Benefícios.

\begin{abstract}
We are living in a period of enormous technological transformations and the organizations face new opportunities that the IS/IT implementations provide, hoping that these investments will help to increase productivity and business prosperity. Meanwhile, several studies performed in public and private sectors have proven that the investments done in IS/IT have not brought the expected benefits. One of the crucial aspects of the IS/IT investments management is the identification of the potential benefits and the guarantee that these benefits will be achieved.
\end{abstract}


The identification of business benefits is difficult, namely the intangible benefits. Additionally, there is strong evidence that traditional financial methods are not suitable to evaluate IS/IT investments. As a consequence, organizations should implement correct benefit management methods. In this paper the authors selected a management approach for IS/IT investments governance, by comparing four known management evaluation frameworks.

Key-words: IS/IT investments; IS/IT governance, IS/IT Benefits Business, Benefits management realization, Benefits management

\section{Introdução}

Os Sistemas e Tecnologias de Informação (SI/TI) representam desafios tecnológicos sofisticados e complexos, que requerem preparação para serem compreendidos, dominados e explorados de uma forma efectiva e eficaz. Estas tecnologias abrem um vasto leque de oportunidades, são facilitadores de desenvolvimento e o seu enorme potencial tem forte impacto na estratégia organizacional. A introdução de novas tecnologias implica mudanças organizacionais que têm de ser planeadas e geridas de forma a assegurar que são atingidos os objectivos pretendidos (Stacey, 1998). As expectativas criadas pela indústria dos SI/TI não são habitualmente realistas em relação à evidência dos benefícios obtidos hoje, em que estamos a implementar aplicações mais complexas, abrangentes e sofisticadas do que realmente necessitamos. Torna-se portanto difícil relacionar directamente as melhorias de desempenho do negócio com os investimentos específicos em aplicações de SI/TI e o foco na obtenção de um retorno financeiro de curto prazo ignora por vezes muitos dos benefícios alcançáveis a médio e longo prazo. Muitas vezes a causa da não obtenção dos benefícios esperados está mais relacionada com a dificuldade de lidar com a complexidade dos investimentos do que com a falta de uma infra-estrutura para os alcançar (Bradley, 2006). Thorp (1998) aponta ainda que, frequentemente os investimentos são entregues dentro do prazo e orçamento previsto, porém os benefícios esperados não são concretizados. Ashurst e Dohery (2003) referem que grande parte das organizações tem adoptado os princípios tradicionais para a avaliação do sucesso dos seus projectos, nomeadamente, no que respeita à entrega em tempo, no orçamento e com a qualidade esperada, não existindo evidência explícita de entrega de benefícios. Winter et al., (2006) e Thiry (2002) alertam para a necessidade de práticas alternativas de gestão que considerem aspectos mais subjectivos, como a geração de valor e de benefícios. Tais alternativas devem representar melhor a complexidade prática da gestão de investimentos em contexto social e político, em constante mutação, desvinculando-se dos tradicionais modelos que simplificam esta realidade (Winter et al., 2006). Reiss et al., (2006) referem que os investimentos raramente geram benefícios directamente, criam somente as capacidades para estes sejam gerados, e é a combinação das diferentes acções e produtos entregues que irá gerar essa capacidade. A gestão de benefícios surge, portanto, como uma alternativa às práticas tradicionais de gestão. Propõe um processo contínuo de visualização dos benefícios, implementando e acompanhando os resultados intermédios e dinamicamente procede ao ajuste necessário do processo para que os benefícios sejam alcançados (Thorp, 1998). Por razões competitivas muitas empresas têm de efectuar investimentos em SI/TI para os quais não encontram a correspondente justificação financeira. As avaliações práticas 
destes investimentos não suportam suficiente sustentação para a realização dos investimentos (Willcocks e Lester, 1997). São muitas as razões do insucesso dos investimentos SI/TI em concretizar valor (value for money) e os contributos para a resolução desta problemática também são diversos. Parece ser um denominador comum o facto de nas organizações a avaliação do sucesso dos investimentos se ter reduzido, simplesmente, ao cumprimento dos prazos, custos e qualidade, esquecendo a medição dos impactos produzidos, as alterações no negócio e/ou os benefícios que potencialmente poderiam ter sido atingidos (Ward e Daniel, 2006). Muitas organizações procuram benefícios apenas do ponto de vista financeiro, o que tem resultado num desperdício de energia, tempo e dinheiro. É muito comum as empresas focarem-se mais no "funciona?", do que em aspectos tais como, por exemplo, "foi adoptado com sucesso?” ou “está a entregar valor?”. Na era da informação, o negócio passou a criar e desenvolver activos intangíveis, nomeadamente, relações com clientes, competências, conhecimento dos colaboradores, tecnologias de informação e uma cultura corporativa que encoraja à inovação, à resolução de problemas e à tomada de decisão. Os activos intangíveis passaram a ser a maior fonte de vantagem competitiva das organizações, e, não existe nenhuma ferramenta que os descreva ou que quantifique os valores que são capazes de gerar. O valor não reside no activo por si só, mas emerge do conjunto de activos e da estratégia que os integrou visando atingir certos objectivos. A maioria das abordagens de gestão de benefícios foi desenvolvida como guia prático em torno de investimentos em SI/TI, efectuados sobretudo em organizações privadas (Ward et. al., 1995), tendo vindo a ser reconhecida de forma crescente a sua importância na obtenção de benefícios desses investimentos.

\section{O desafio}

A Estereofoto Geoengenharia, SA é uma organização fundada em 1973, estabelecida internacionalmente em vários países, Brasil, Moçambique e Leste Europeu, líder nacional na aplicação de soluções tecnológicas suportadas em produtos de base geográfica digital, com obra desenvolvida transversalmente em variados domínios, nomeadamente, infra-estruturas rodoviárias, redes eléctricas, redes municipais, gasodutos, cadastros temáticos entre outros. No âmbito de uma candidatura ao QREN ${ }^{1}$, foi aprovado um projecto de investimento na área dos sistemas e tecnologias de informação para o desenvolvimento de um sistema dinâmico de gestão e manutenção de infra-estruturas rodoviárias, com o auxílio de ferramentas de medição e posicionamento GPS, suportadas em produtos digitais fotográficos, de vídeo e laser. Esta solução permite a recolha automática geo-referenciada de toda a infra-estrutura disponível para posterior gestão e exploração estatística com benefícios evidentes no suporte à tomada de decisão. Tal facto colocou à organização candidata a questão de como e qual seria a mais adequada ferramenta de gestão para potenciar e salvaguardar

1 O Quadro de Referência Estratégico Nacional constitui o enquadramento para a aplicação da Política Comunitária de Coesão Económica e Social em Portugal no período 2007-2013. O QREN define as orientações fundamentais para a utilização nacional dos fundos comunitários com carácter estrutural e para a estruturação dos programas operacionais temáticos e regionais. 
a concretização dos benefícios inerentes ao referido investimento. A resposta a esse desafio passou por um processo de investigação com a seguinte sequência. Numa primeira fase foi desenvolvida uma pesquisa bibliográfica tendo sido identificadas quatro abordagens para análise. Posteriormente, num processo iterativo de comparação, primeiramente mais "amplo" (atributos aplicados a quatro abordagens) e depois mais "fino" (critérios aplicados a duas abordagens), foi escolhida a abordagem que pareceu garantir, com maior fiabilidade, os objectivos propostos para o investimento em causa. A aplicação do processo está documentada no ponto que se segue.

\section{As abordagens}

\subsection{Cranfield School (CS)}

Este modelo permite ao investidor estudar a viabilidade dos investimentos em SI/TI e criar mecanismos que contribuem para a realização dos benefícios esperados. Esta aproximação dá especial atenção a três aspectos importantes: (1) Os fins - A melhoria da performance dos objectivos. (2) As formas - As transformações necessários pelas quais a organização deve passar para cumprir os objectivos estabelecidos. (3) Os meios - Potenciar as capacidades dos recursos SI/TI. A resposta a estas questões é dada pela construção de uma rede de causa-efeito, conhecida como Rede de Dependência de Benefícios (RDB) onde se reflecte a forma como as melhorias podem ser obtidas, através da combinação de mudanças e alterações que o negócio tem de realizar, suportado no desenvolvimento total das potencialidades do SI/TI. Esta rede fornece um robusto business case para os investimentos e para as mudanças necessárias, reforçando a fiabilidade da entrega dos benefícios definidos. Segundo Peppard e Ward (2002), qualquer que seja a metodologia a seguir para a realização de benefícios deve considerar os seguintes cinco princípios: (1) SI/TI por si só não traz valor acrescentado. Ter simplesmente a tecnologia não dá qualquer benefício. $\mathrm{O}$ valor da tecnologia não está na sua posse. (2) Os benefícios surgem, quando o SI/TI permite às pessoas fazerem o seu trabalho de forma diferente. Os benefícios emergem sempre que os colaboradores fazem o seu trabalho de uma forma eficiente. (3) Somente os gestores e os utilizadores podem entregar benefícios. Os benefícios resultam de mudanças ou inovações na forma de trabalhar. (4) Todos os projectos de investimento em SI/TI tem resultados, mas nem todos são benefícios. Na realidade são muitos os exemplos em que os resultados são negativos colocando as próprias organizações em perigo de sobrevivência. (5) Benefícios têm de ser activamente geridos para serem obtidos. Os benefícios não são resultados que automaticamente ocorram. A gestão destes benefícios deve prosseguir até que se verifique a realização de todos os benefícios esperados. A construção de um plano de realização de benefícios (Peppard e Ward, 2004) obriga à resposta a sete questões fundamentais. Uma das características fundamentais destas sete questões é que elas focam-se na organização e nas transformações necessárias e não na tecnologia. Outra importante característica é que as questões são respondidas por um conjunto alargado de colaboradores, gestores, utilizadores e demais interessados e não centradas num único indivíduo. As questões fundamentais são: (1) Por que queremos melhorar? (2) Que melhorias são necessárias ou possíveis? (3) Que benefícios serão realizados por cada stakeholder? (4) Quem é o 
responsável por cada benefício? (5) Que mudanças são necessárias para atingir cada benefício? (6) Quem é o responsável por cada mudança com sucesso? (7) Como e quando podemos identificar os benefícios realizados?

Na Tabela 1, são identificadas todas as fases do processo de gestão de benefícios e discriminadas as actividades correspondentes.

Tabela 1 - Processo de gestão de benefícios (Ward e Daniel, 2006, 119)

\begin{tabular}{lll} 
No & \multicolumn{1}{c}{ Fase } & \multicolumn{1}{c}{ Actividade } \\
\hline 1 & $\begin{array}{l}\text { Identificar e estruturar } \\
\text { benefícios }\end{array}$ & $\begin{array}{l}\text { Estabelecer ligações directas entre drivers, objectivos e benefícios. } \\
\text { Analisar os drivers para obter os objectivos de investimentos. Identificar } \\
\end{array}$ \\
& $\begin{array}{l}\text { os benefícios resultantes da obtenção dos objectivos. Estabelecer a } \\
\text { propriedade dos benefícios. Identificar as mudanças requeridas e a } \\
\text { oposição dos stakeholders. Construção do business case. }\end{array}$ \\
\hline
\end{tabular}

2 Plano de realização de benefícios

Finalização das medições dos benefícios e das mudanças requeridas. Obtenção do acordo de todos os stakeholders para a responsabilização e para a propriedade dos benefícios e das mudanças. Aprovação do business case suportado num plano de realização de benefícios.

3 Executar o plano de Gerir as transformações do negócio. Seguir os benefícios até à sua plena benefícios realização.

\begin{tabular}{ll}
\hline $\begin{array}{l}\text { Rever e avaliar } \\
\text { resultados }\end{array}$ & $\begin{array}{l}\text { Avaliar se os benefícios foram atingidos. Lições aprendidas (Lessons } \\
\text { learned) }\end{array}$
\end{tabular}

5 Potencial para benefícios Identificar novos benefícios. Identificar benefícios adicionais futuros

Este modelo segue três grandes princípios que o tornam potenciador de uma gestão eficaz: (1) É um processo orientado à tomada de decisão em investimentos SI/TI. (2) Promove a maximização dos benefícios associados ao investimento. (3) Permite monitorizar a implementação do investimento.

\subsection{Gerindo programas com sucesso (GPS)}

O Office of Government Commerce é um gabinete autónomo do ministério das finanças do Reino Unido que trabalha com organizações do sector público, auxiliandoas na melhoria da sua eficácia e eficiência, na optimização as suas actividades comerciais, na construção dos business cases, com o foco principal da entrega de projectos e programas com sucesso. O objectivo do modelo é garantir que as esperadas mudanças de negócio sejam claramente definidas e providenciem um business case robusto, assegurando que os benefícios sejam plenamente atingidos. O business case é a ferramenta principal desta aproximação e define o racional para o investimento, suportando uma sustentada análise para uma realista tomada de decisão. Qualquer programa de mudança requer um constante foco nos pretendidos benefícios, mantendo-se alinhado com os objectivos do negócio. A análise custo-benefício tradicionalmente procura demonstrar que os retornos financeiros justificam a opção escolhida e que os custos podem ser controlados e geridos de forma eficaz. Na realidade nem todos os benefícios podem ser mensurados financeiramente; Os benefícios qualitativos ou menos tangíveis são em geral mais difíceis de quantificar e necessitam de ser identificados e acompanhados. Os custos e benefícios mudam ao longo do tempo, o que requer uma continuada actualização do business case. Por estas razões, 
uma simples fotografia tirada no início do programa pode não ser adequada para reflectir as interdependências ou mudanças exteriores. Uma continuada actualização do business case é a chave para a revisão do progresso na direcção dos resultados, efectuando os inevitáveis ajustamentos. Este enquadramento relaciona as dependências entre o processo de gestão de benefícios e os diversos passos até à entrega do programa de benefícios. A gestão de benefícios começa ainda antes do início do programa aprovado. Somente as iniciativas de mudança que apresentam uma estratégia de benefícios definida obtêm a aprovação. A identificação, o acompanhamento e a realização de benefícios continuam através do programa e provavelmente terminaram já com o projecto fechado. A Estratégia de Gestão de Benefícios descreve um estruturado e continuo processo para garantir que os benefícios são sustentados e o retorno do investimento é o máximo. Os resultados são a chave para entregar os benefícios, porque são estes que auxiliam a formular as respostas às seguintes questões: (1) Quais são os benefícios estratégicos e quais são os principais papéis e responsabilidades? (2) Quem mais é interessado? É necessário envolvê-lo? (3) Quais as sequências e as dependências entre benefícios? (4) Qual é o valor, o calendário e o perfil para cada benefício? (5) Quais os pressupostos, custos, riscos associados à realização de cada benefício? (6) Como poderão ser seguidos e medidos os benefícios? A resposta a estas questões representa o enquadramento de um processo documentado na Estratégia de Gestão de Benefícios.

\subsection{Gestão de benefícios em projectos (GBP)}

O processo de planeamento e execução de um projecto tem sido tipicamente limitado ao âmbito do gestor de projectos (Melton et al., 2008). Também de acordo com Melton et al., (2008), tem sido igualmente reconhecido que a única finalidade de um projecto é trabalhar off line e de forma business as usual (BAU) para introduzir mudanças organizacionais que em última análise, são um benefício para o negócio. O processo de gestão de benefícios tem sido visto como o processo global de negócios que encaixa o projecto dentro da empresa. Por isso, é claro que a gestão de benefícios é parte integrante da gestão de projectos e do ciclo de vida do projecto. A gestão de benefícios de projectos (Melton et al., 2008) pode ser definida como um processo de negócios que une a razão da execução de projectos com o impacto que a entrega destes tem no negócio. Melton (2008, 28) refere ainda que "os projectos são meios que as organizações utilizam para atingir os objectivos, não os fins em si mesmo”. Nesta abordagem, os autores referem que a estratégia deverá ser o ponto de partida para qualquer investimento a ser realizado na organização. As forças e as fraquezas da organização devem ser identificadas através do modelo das cinco forças de Porter com recurso à utilização da análise SWOT. A importância de alinhar os projectos com a estratégia da organização é crucial. O processo da gestão de benefícios inclui tipicamente 3 etapas: (1) A identificação do benefício - identificação do tipo de benefícios que a organização ou o projecto pretendem atingir. (2) A especificação dos benefícios - definição concreta dos benefícios, das métricas de avaliação que podem ser entregues em alinhamento com a organização. (3) A realização dos benefícios - A entrega dos benefícios, durante, no final ou após a realização do projecto. Cada um dos três processos tem uma ligação directa à organização ou ao projecto, ao objectivo, ou ao âmbito. É esta ligação que diferencia a gestão de benefícios dos outros processos de negócio. Alinha todas as actividades do negócio com a estratégia organizacional. A 
gestão de benefícios providencia a todas as partes envolvidas no negócio, e de forma mensurável, a justificação da realização de determinada actividade e a sua importância para o futuro da organização. Dota o gestor de projecto de um conhecimento profundo da razão do projecto, da importância de atingir os objectivos e benefícios, e das métricas que tem que ser seguidas para a sua concretização. De acordo com Melton (2008) uma visão clara de sucesso resulta da combinação das actividades das fases 1 a 4 associados a factores críticos de sucesso: (1) Estratégia do negócio - Este é o ponto de partida para a gestão de benefícios uma vez que organiza o contexto de negócio para todas as decisões subsequentes. (2) Compromisso do patrocinador - Uma gestão de benefícios com sucesso necessita de um efectivo patrocínio por todos os níveis da organização. (3) Gestão de mudança - Os projectos são as formas para provocar as mudanças nas organizações. (4) Portfólio da mudança - Para que ocorram mudanças no negócio é necessário um portfólio de projectos. O sucesso do processo de gestão de benefícios está na correcta gestão do portfólio com o objectivo de atingir os benefícios nos prazos e locais esperados. (5) Processo Stage Gates - No ciclo da gestão de benefícios existem perguntas chave que devem ser colocadas: (1) É o projecto correcto? (2) Traz este projecto valor adicional? (3) Está este projecto adequadamente planeado para entregar benefícios? (4) Está este projecto a seguir na direcção correcta? A forma adequada para lidar com estas questões é através do processo Stage Gates. (6) Especificações e acompanhamento de benefícios - A especificação e acompanhamento dos benefícios pode ocorrer em qualquer fase do ciclo de vida do projecto. O ciclo de vida da gestão de benefícios é uma ligação contínua entre o projecto e o negócio, através do seu ciclo de vida (Melton, 2008).

\subsection{Balanced Scorecard (BSC)}

Os gestores na actualidade necessitam de um instrumento de gestão que reflicta em cada momento a situação da organização, permitindo guiar as organizações utilizando indicadores de performance não exclusivamente financeiros. Kaplan e Norton (1992 e 1996) foram os primeiros a defender a necessidade de um modelo de indicadores de desempenho financeiro e não financeiro que auxiliassem os gestores a avaliar o sucesso nas organizações. O Balanced Scorecard (BSC) diferencia-se dos outros modelos de gestão porque ele agrega todos os modelos de controlo financeiro e não financeiro existentes na organização. De acordo com Kaplan e Norton (1996), o BSC, não se limita a um simples modelo de medida do desempenho, trata-se de um veículo de comunicação e implementação da estratégia. O BSC organiza os indicadores em quatro perspectivas; financeira, clientes, processos internos, aprendizagem e crescimento, e que reflecte o equilíbrio (balanced) entre objectivos de longo e curto prazo, indicadores financeiros e não financeiros, entre resultados alcançados e desempenhos interno e externo. A maioria das estratégias definidas pelas organizações nunca chega na prática a uma efectiva implementação, vários estudos confirmam esta afirmação. As razões potenciais para este insucesso prendem-se principalmente com os problemas comunicacionais dentro da empresa, falta de envolvimento dos colaboradores com os objectivos da empresa, falta de alinhamento dos objectivos globais com os objectivos dos departamentos e dos trabalhadores, falta de alinhamento com os objectivos a longo prazo e inexistência de indicadores para controlo dos factores críticos. Os indicadores financeiros não são suficientes para medir a capacidade de criação de valor para as empresas e para o cliente, nomeadamente, o valor do capital intelectual, qualidade do 
serviço, qualidade dos processos, tecnologia e inovação. Para alcançar vantagens competitivas, sustentadas no tempo, é necessário, entre outros factores, equilibrar a gestão financeira com o capital intangível da empresa. Uma vez definida a visão e a missão da organização é fundamental constituir um plano fundamentado numa estratégia aprovada pela gestão de topo, a qual, deve ter por base as competências, os recursos e as capacidades que são os pilares da vantagem competitiva sustentada da organização. O BSC é um modelo de gestão estratégica que traduz a visão e estratégia da organização num conjunto de objectivos interligados, medidos através de indicadores associados aos factores críticos. O BSC permite comunicar a visão e a estratégia a toda a organização, bem como o acompanhamento da sua execução, através de um conjunto de indicadores distribuídos pelas quatro perspectivas anteriormente identificadas. Um dos méritos apontados ao BSC relaciona-se com a possibilidade de proporcionar uma profunda reflexão interna, na qual cada unidade na cadeia de valor se encontra obrigada a identificar os seus objectivos, os seus factores chave de sucesso e as suas áreas de interdependência com as outras unidades. Segundo os criadores do BSC, o conjunto de indicadores de desempenho tem de ser escolhido de modo coerente com a visão, missão e estratégia organizacional, num processo de desdobramento hierárquico decrescente (top-down). A construção e definição de indicadores devem ser realizadas na fase de planeamento, quando se determina a missão e a estratégia da empresa, os factores críticos de sucesso, as metas de desempenho a alcançar, os indutores desses resultados e os indicadores de causaefeito, para posterior controlo. O BSC vê a organização sobre quatro perspectivas: (1) Financeira - O que devemos fazer para satisfazer as expectativas dos accionistas? (2) Clientes - O que devemos de fazer para satisfazer as expectativas dos nossos clientes? (3) Processos Internos - Em que processos devem ser excelentes para atingir a nossa visão? (4) Aprendizagem e Crescimento - Quais os aspectos críticos para manter a excelência? As perspectivas desdobram-se em objectivos, que por sua vez são compostos por indicadores. As perspectivas, objectivos e indicadores são integrados através de factores de ponderação. Esta metodologia tem como ferramenta central um mapa estratégico orientado por relações causa-efeito. É importante que nenhuma perspectiva funcione de forma independente.

\section{Comparativo das abordagens}

De acordo com Sapountzis et al., (2008), desde 1995, devido ao reconhecimento da importância da gestão e realização de benefícios, várias abordagens têm sido desenvolvidas para ajudar as organizações a identificar, monitorizar e alcançar os benefícios a que se propõem. Sapountziz et al., (2007), referem que nem todas as abordagens conduzem os projectos aos benefícios. Algumas delas ocorrem apenas no fim do projecto, actuando como instrumento que permite a avaliação dos investimentos. Neste ponto resumem-se as abordagens de gestão de benefícios que foram estudadas para a realização deste trabalho, evidenciando as diferenças nas suas características principais, nos processos e actividades, e finalmente nas funções e responsabilidades. 
Tabela 2 -Principais diferenças entre abordagens

\section{Características principais}

\section{Cranfield School (Ward e Daniel, 2oo6)}

Comparação dos resultados do projecto com o plano de realização dos benefícios durante o projecto. Avalia se ocorreu alguma alteração interna ou externa que afecte a realização dos benefícios planeados. A identificação de novos benefícios inicia a um novo plano para a sua realização. Processo orientado para apoio da tomada de decisão em investimentos SI/TI que procura a maximização dos benefícios.

\section{Gerindo Programas com Sucesso (OGC, 2007)}

Identifica a gestão de benefícios como uma actividade nuclear num processo contínuo suportado por um programa. A gestão de benefícios inicia-se antes do projecto ou programa ser aceite, mas só aqueles com uma estratégia de benefícios bem definida obtêm a aprovação. A identificação, a monitorização e a realização de benefícios cruzam o programa e continuam mesmo depois do seu encerramento. $\mathrm{O}$ business case é a ferramenta principal para lidar com os benefícios através do projecto.

\section{Gestão de Benefícios em Projectos (Melton, 2008)}

Esta abordagem foca-se nas fases típicas da gestão de projectos e utiliza os factores de sustentabilidade como Stage Gates para a realização de benefícios. O processo de gestão de benefícios está ligado ao scorecard de benefícios e utiliza os seguintes seis factores críticos de sucesso: (1 )Estratégia de Negócio, (2 )Captação de Patrocínios, (3) Gestão da Mudança no Negócio, (4 )Portfólio de Mudança, (5) Processo Stage Gates, (6) Especificação e acompanhamento de benefícios.

\section{Balanced Scorecard (Kaplan e Norton, 1996)}

Nesta abordagem reflecte-se o equilíbrio entre: Objectivos de longo prazo e de curto prazo, indicadores financeiros e não financeiros, resultados alcançados e vectores de desempenho, desempenho interno e externo em harmonia com as quatros perspectivas: (1) Financeira, (2) Clientes, (3) Processos Internos e (4) Aprendizagem e crescimento.

\section{Processos e actividades}

\section{Cranfield School (Ward e Daniel, 2oo6)}

Fase 1 - Identificar e estruturar os benefícios, Fase 2 - Plano de realização de benefícios

Fase 3 - Executar o plano de benefícios, Fase 4 - Rever e avaliar resultados

Fase 5 - Potencial de benefícios futuros

\section{Gerindo Programas com Sucesso (OGC, 2007)}

Processo de gestão de benefícios, gestão estratégica dos benefícios, plano de realização dos benefícios, identificação e priorização de benefícios, optimização do mix de benefícios, realização, monitorização dos benefícios e avaliação.

\section{Gestão de Benefícios em Projectos (Melton, 2008)}

Identificação, especificação e realização dos benefícios, fases do projecto e factores críticos de sucesso

\section{Balanced Scorecard (Kaplan e Norton, 1996)}

Não tem processo de gestão de benefícios. Cada unidade obriga-se definir os seus objectivos, os seus factores chave de sucesso e as interdependências com as outras unidades numa lógica de causa-efeito 


\section{Funções e responsabilidades}

\section{Cranfield School (Ward e Daniel, 2006)}

Dono do benefício - responsável por atingir o benefício, dono da mudança - responsável por fazer acontecer a mudança no negócio, patrocinador - responsável do projecto e gestores de projecto das diversas áreas e responsáveis por diferentes áreas de negócio

\section{Gerindo Programas com Sucesso (OGC, 2007)}

Sénior responsável - Estratégia da Gestão de Benefícios e Plano de Realização de Benefícios.

Gestor de Programa - Plano de Realização de Negócios e business case.

Gabinete de Programa - Monitorização do progresso da obtenção dos benefícios.

Gestor das mudanças de negócio - Realização dos benefícios; perfil; análise de impacto; gerir o risco.

Gestor de Projecto - Definição de benefícios, gestão do tempo, custo e qualidade.

\section{Gestão de Benefícios em Projectos (Melton, 2008)}

Patrocinador - O patrocinador do projecto e Gestor do projecto - Responsável do projecto

Utilizador final - Beneficiários (Colaboradores, Fornecedores, Competidores e Clientes )

\section{Balanced Scorecard (Kaplan e Norton, 1996)}

Foco claro na satisfação dos accionistas e clientes. Apresenta uma abordagem de partilha de responsabilidade. O BSC não tem uma abordagem até às tarefas logo as responsabilidades são atribuídas a grupos. Não existe uma individualização de responsabilidades

Da análise das tabelas 2 verifica-se que o Balanced Scorecard não é uma abordagem vocacionada à prossecução de benefícios, mas sim, uma ferramenta global de comunicação e organização, com um objectivo muito claro de alinhamento de todas as iniciativas de investimento com a estratégia do negócio. O BSC está muito focalizado num stakeholder específico, os accionistas, não reconhecendo a importância da contribuição que os colaboradores e fornecedores têm na realização dos objectivos da empresa. Como seria expectável, todas as restantes abordagens apresentam semelhanças e diferenças devidas à situação de terem sido criadas em contextos diversos, umas mais focadas em organismos públicos ou privados e outras em gestão de projectos. A abordagem GPS assume uma óptica muito centrada na gestão de benefícios no âmbito de programas, numa lógica mais institucional, com uma dinâmica mais no médio/longo prazo típico das organizações governamentais. Desta forma, não se revelou adequada à especificidade do projecto em estudo. Assim, as abordagens aplicáveis resumem-se ao modelo de Cranfield School de Ward e Daniel (2006) e ao modelo de Melton (2008), a Gestão de Benefícios em Projectos, para as quais se apresenta, na Tabela 3, uma comparação mais detalhada. 
Tabela 3 - Comparação detalhada de duas abordagens

\section{Comparação detalhada entre as duas abordagens}

Gestão de Benefícios em Projectos (Melton,2008).

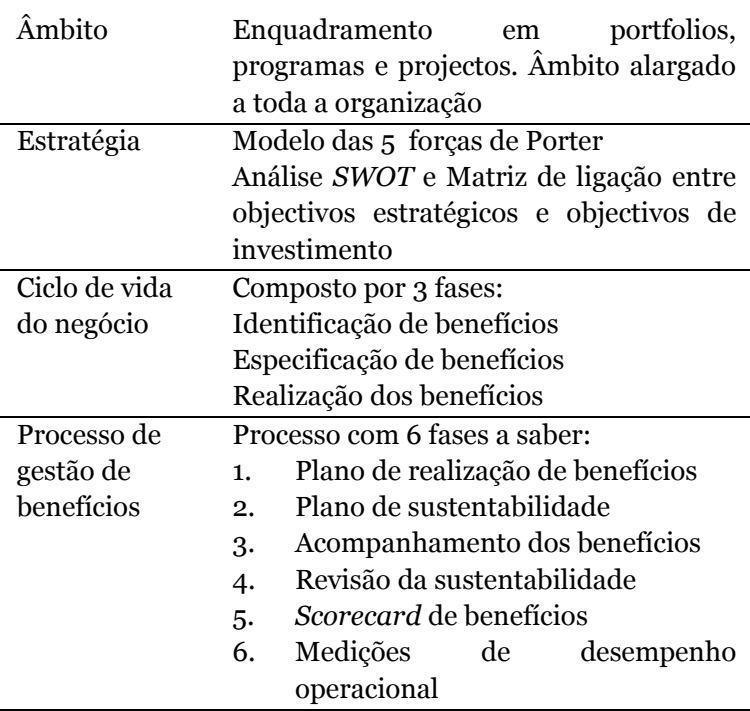

Ferramentas Fase 1 - Identificação de benefícios:
Mapeamento dos benefícios, matriz de benefícios e scorecard de benefícios

Fase 2 - Especificação de benefícios: Definição do âmbito, lista de verificação do âmbito, lista de verificação do ambiente de negócio, matriz de influência dos benefícios e Business case template.

Fase 3 - Realização de benefícios: Análise de risco, Análise de satisfação dos clientes e Análise de satisfação do negócio

\begin{tabular}{ll}
\hline Recurso a & Não define exactamente quantos \\
técnicas do & workshops se realizam. \\
tipo & São vários na fase de desenho do \\
workshop & projecto.
\end{tabular}




\begin{tabular}{|c|c|c|}
\hline $\begin{array}{l}\text { Relação com } \\
\text { metodologias } \\
\text { de gestão de } \\
\text { projecto }\end{array}$ & $\begin{array}{l}\text { Está mais alinhada, ao planeamento dos } \\
\text { processos de negócio. Esta metodologia } \\
\text { tem um enquadramento de ciclo de vida } \\
\text { de gestão de benefícios com o ciclo de } \\
\text { vida da gestão de projectos. }\end{array}$ & $\begin{array}{l}\text { É uma metodologia complementar que se } \\
\text { enquadra nas principais metodologias de } \\
\text { gestão de projectos. } \\
\text { Esta abordagem aconselha à utilização das } \\
\text { melhores práticas. }\end{array}$ \\
\hline $\begin{array}{l}\text { Benefícios } \\
\text { não esperados }\end{array}$ & $\begin{array}{l}\text { Início um novo projecto na prossecução } \\
\text { dos novos benefícios }\end{array}$ & $\begin{array}{l}\text { cia os benefícios não esperados. } \\
\text { cio a um novo plano de realização. }\end{array}$ \\
\hline $\begin{array}{l}\text { Ligação aos } \\
\text { conceitos de } \\
\text { programa e } \\
\text { portfólio de } \\
\text { aplicações }\end{array}$ & $\begin{array}{l}\text { A ligação ocorre através do factor crítico } \\
\text { de sucesso do processo de gestão de } \\
\text { benefícios. } \\
\text { FCS4-Portfólio da mudança } \\
\text { Garantia de que os benefícios correctos } \\
\text { são obtidos nos locais certos. }\end{array}$ & $\begin{array}{l}\text { Foca-se essencialmente em dois quadrantes } \\
\text { do portfólio de aplicações: } \\
\text { Operacional - aumento de desempenho } \\
\text { em actividades já existentes. } \\
\text { Suporte - aumento da produtividade de } \\
\text { tarefas associadas à gestão da empresa bem } \\
\text { como o cumprimento dos requisitos legais. }\end{array}$ \\
\hline $\begin{array}{l}\text { Técnicas de } \\
\text { gestão de } \\
\text { stakeholders }\end{array}$ & $\begin{array}{l}\text { Utiliza o ciclo de vida da gestão da } \\
\text { relação que compreende } 4 \text { fases: } \\
\text { Fase } 1 \text { - Inicio da relação, Fase } 2 \text { - } \\
\text { Contratação, Fase } 3 \text { - Compromisso e } \\
\text { Fase } 4 \text { - Desligamento }\end{array}$ & $\begin{array}{l}\text { Utiliza as duas técnicas para gestão de } \\
\text { stakeholders seguintes;Atribuição de } \\
\text { prioridades às atitudes dos stakeholders e } \\
\text { quatro perfis de stakeholders (Benjamim e } \\
\text { Levinson,1993); Cooperantes, Campeões, } \\
\text { Comprometidos e Resistentes }\end{array}$ \\
\hline $\begin{array}{l}\text { Factores } \\
\text { críticos de } \\
\text { sucesso }\end{array}$ & $\begin{array}{l}\text { O sucesso da implementação do projecto } \\
\text { depende de seis factores críticos de } \\
\text { sucesso. }\end{array}$ & $\begin{array}{l}\text { Não atribui relevância aos factores críticos } \\
\text { de sucesso do projecto de gestão de } \\
\text { benefícios, mas foca-se nos factores críticos } \\
\text { para a mudança na organização. }\end{array}$ \\
\hline
\end{tabular}

\section{Discussão e selecção da abordagem}

O âmbito das abordagens é comum e tem como principal finalidade a gestão de benefícios e o seu enquadramento em investimentos que produzam alterações nos processos da organização, quer pela utilização do SI/TI ou pelo simples redesenho dos processos. As duas abordagens têm a preocupação do alinhamento dos novos investimentos com as linhas estratégicas da organização e ambas não substituem a gestão de projectos, mas antes completam-na. De salientar também que estas abordagens fazem uma ligação ao portfólio de aplicações da organização e utilizam também a técnica de gestão de stakeholders.

A abordagem de Melton et al., (2008) está em alguns aspectos mais alinhada com o planeamento de processos de negócio e tem um ciclo de vida claramente definido. A abordagem de Ward e Daniel (2006) assume-se mais como o processo-chave em torno do qual se interligam os diferentes processos da organização. Constatou-se que ambas as abordagens utilizam propostas de outros autores para a formulação das estratégias. Efectuada a análise comparativa mais detalhada, constatou-se que as três principais razões que influenciaram a decisão da opção pelo modelo de Cranfield School foram as seguintes:

1. A abordagem de Melton et al., (2008) recorre a um plano de sustentabilidade e a um scorecard de benefícios. O processo de Ward e Daniel (2006) tem um carácter interactivo e não termina no final do projecto, explorando o potencial de benefícios futuros, iniciando um novo ciclo/plano de benefícios sempre que ocorre um benefício não esperado. Tal, enquadra-se perfeitamente na 
estratégia de negócio da organização e do presente estudo de caso, uma vez que procura benefícios a partir de projectos que desenvolve junto dos seus clientes.

2. A abordagem de Cranfield School centra a sua atenção na rede de dependência de benefícios, uma representação gráfica de fácil leitura e que permite identificar, de uma forma eficaz, como as alterações ao negócio impulsionadas na utilização de SI/TI fazem obter os benefícios previstos no business case. A abordagem de Melton et al., (2008) centra-se num conjunto de ferramentas que se distribuem pelas três fases do processo de gestão de benefícios, originando alguma complexidade e podendo gerar alguma dificuldade na implementação do modelo.

3. Os factores críticos de sucesso na abordagem de Melton et al., (2008), circunscrevem-se somente ao sucesso do projecto, enquanto na abordagem de Ward e Daniel (2006) os factores para a mudança são mais abrangentes, potenciam a mudança e obtenção de benefícios promovendo o sucesso da organização. A abordagem de Cranfield School apresenta uma vertente estratégica, transversal a toda a organização, promovendo a aplicação e obtenção de alinhamento estratégico. A abordagem de Melton et al., (2008), direcciona-se mais para a gestão do projecto e da mudança por ele produzida.

\section{Conclusões}

A abordagem de Cranfield School oferece uma proposta estruturada que permite a identificação, monitorização e realização dos benefícios previstos, garantindo que as acções necessárias para a sua concretização são identificadas e ainda que são tomadas as decisões adequadas para garantir o sucesso do plano de realização de benefícios adoptado.

A abordagem foi desenvolvida de forma a poder coexistir com outras abordagens, nomeadamente, aquelas que gerem projectos ou programas, trazendo a mais-valia da gestão de benefícios, de uma forma complementar.

A abordagem de Cranfield School fornece também uma base para a avaliação da viabilidade de um programa ou projecto, em termos de retornos mensuráveis esperados em relação aos custos envolvidos, permitindo um planeamento detalhado, gestão e avaliação da realização de cada benefício.

Finalmente, o processo inerente a esta abordagem encoraja as partes interessadas a um comprometimento e partilha do conhecimento colectivo, reforçando uma maior integração e complementaridade das várias iniciativas e investimentos em curso na organização.

A escolha da abordagem de Cranfield School auxiliou na identificação clara e inequívoca dos diferentes tipos de benefícios, tangíveis e intangíveis, e possibilitou o desenho de uma rede de dependências que permitiu gerir a complexidade das mudanças organizacionais requeridas para a obtenção plena dos benefícios inicialmente definidos. 


\section{Referências}

Ashurst, C. e Doherty, N. F. (2003), Towards the formulation of "a best practice" framework for benefits realization in IT projects. Electronic Journal of Information Systems Evaluation 6, 1-10.

Bradley, G., (2006), Benefit Realization Management: A Practical Guide for Achieving Benefits through Change, Gower.

Kaplan, R.S. e Norton D.P. (1992) Balanced Scorecard: Measures that drive performance, Harvard Business Review, January-February 1992.

Melton, T. (2008), Real Project Planning: Delivering a Project Delivery Strategy, Elsevier, Oxford, Great Britain.

Melton, T., Smith P. e Yates J. (2008), Project Benefits Management: Linking projects to the Business, Elsevier, Oxford, Great Britain.

OGC, Office of Government Commerce (2007b), STDK Home, Delivery Lifecycle: Benefits Management, www.ogc.gov.uk/sdtoolkit/reference/deliverylifecycle/

OGC, Office of Government Commerce (2007a), Managing Successful Programs MSP, The Stationery Office, London.

OGC, Office of Government Commerce (2004), Project Initiation Guidelines, www.ogc.gov.uk.

OGC (Office of Government Commerce): Managing Benefits: An Overview. [Electronic]. Accessible: http://www.ogc.gov

The Effective Measurement and OGC (Office of Government Commerce): Management of ICT Costs and Benefits. [Electronic]. Accessible: http://www.ogc.gov.uk/documents/ManagingBenefitsV101.pdf.

Peppard, P., Ward, J., (2004) Beyond strategic information systems: towards an IS capability, Journal of Strategic Information Systems 13, 167-194

Reiss, G., Anthony, M., Chapman, J., Leigh, G., Pyne, A., Rayner, P. (2006), Gower Handbook of programme management, Gower Publishing.

Sapountzis, S., Yates, K. and Kagioglou (2008), Realising benefits through primary healthcare settings, Facilities, in press.

Sapountzis, S., Harris, K. and Kagioglou, M. (2007), Benefits Realisation Process for Healthcare, 4th International Research Symposium (SCRI), 359-71.

Stacey, M., (1998), Generativity in Organizational Life, Context Management Consulting Inc., www.contextconsulting.com .

Thiry, M. (2002), Combining value and project management into an effective programme management model, International Journal of Project Management, Elsevier Science: Oxford, April 2002, 20 (3), 221-228.

Thorp, J. (1998), The Information Paradox - Realising the business benefits of information technology, Toronto, Canada, McGraw-Hill. 
Ward J. Daniel, E. (2006). Benefits Management, Delivering Value from IS and IT Investments. John Wiley \& Sons, Chichester, UK.

Ward, J., Taylor, P. and Bond P. (1995), Identification, realisation and measurement of IS/IT benefits: an empirical study of current practice, Proceedings of the Second European Conference on Information Technology Investment Evaluation, Henley on Thames.

Willcocks, L., Lester, S. (1997), Assessing IT productivity: Any way out of the labyrinth? Managing IT as a Strategic Resource, McGraw-Hill, London.

Winter, M., Smith, C., Morris, P., Cicmil, S. (2006), Directions for Future Research in Project Management: The Main Findings of UK government-funded research network. International Journal of Project Management, 24, 8, 638-649. 